\title{
Reversible Transdifferentiation: Interconversion of Somatotrophs and Lactotrophs in Pituitary Hyperplasia
}

\author{
S. Vidal, D.V.M., E. Horvath, Ph.D., K. Kovacs, M.D., Ph.D., R. V. Lloyd, M.D., Ph.D., H. S. Smyth M.D., Ph.D. \\ Department of Laboratory Medicine (SV, EH, KK) and Neurosurgery (HSS), St. Michael's Hospital, \\ University of Toronto, Toronto, Ontario, Canada; Department of Anatomy, Laboratory of Histology (SV), \\ University of Santiago de Compostela, Lugo, Spain; and Department of Laboratory Medicine and \\ Pathology (RVL), Mayo Clinic, Rochester, Minnesota
}

Previous studies conclusively demonstrated transformation of somatotrophs into bihormonal mammosomatotrophs in gestational lactotroph hyperplasia during pregnancy. Similar transdifferentiation of somatotrophs into thyrotrophs through bihormonal intermediate thryrosomatotrophs was documented during thyrotroph hyperplasia in both rodent and human pituitaries in hypothyroidism. The cessation of the stimulation resulted in reversal of the process in both conditions. The conversion of lactotrophs into somatotrophs was suggested but not documented previously in the human gland. The present study was undertaken to investigate cases of somatotroph hyperplasia by transmission electron microscopy, immunoelectron microscopy using double immunogold labeling for growth hormone and prolactin, as well as combined immunocytochemistry and in situ hybridization. Adenohypophysial tissue was removed from a 38-year-old man and a 29-year-old woman with longstanding acromegaly due to ectopic overproduction of growth hormone-releasing hormone (GRH) by bronchial carcinoid tumors. For comparison, two pituitary biopsies were studied: one from a 38-year old woman with idiopathic lactotroph hyperplasia and one from a 14-year-old boy with secondary lactotroph hyperplasia due to a suprasellar craniopharyngioma. In the patients with somatotroph hyperplasia, the prevailing cell type was the hyperplastic somatotroph joined by mammosomatotroph deriving from lactotrophs, whereas monohormonal lactotrophs were rare. The predominance of mammosomatotrophs and active lactotrophs was documented in the patient with idiopathic lactotroph hyperplasia, whereas the case of the patient with secondary lactotroph hyperplasia was characterized by monohormonal lactotrophs and so-

Copyright (C) 2001 by The United States and Canadian Academy of Pathology, Inc

VOL. 14, NO. 1, P. 20, 2001 Printed in the U.S.A.

Date of acceptance:

Address reprint requests to: Dr. Eva Horvath, Division of Pathology, St. Michael's Hospital, 30 Bond Street, Toronto, Ontario M5B 1W8 Canada; fax: 416-864-5870. matotrophs, but mammosomatotrophs were rare. That finding in the pituitary of the boy suggests that participation of mammosomatotrophs in lactotroph hyperplasia is not unconditional. Our findings conclusively demonstrate conversion of lactotrophs into mammosomatotrophs during somatotroph hyperplasia, providing further evidence for the potential of reversible transdifferentiation between somatotrophs and lactotrophs in response to functional demand.

KEY WORDS: Growth hormone, Hyperplasia, Immunoelectron microscopy, In situ hybridization, Mammosomatotrophs, Pituitary, Prolactin.

Mod Pathol 2001;14(1):20-28

Adenohypophysial cell multiplication and endocrine activity are dependent upon the coordinated action of a large number of growth factors, cytokines, and neuropeptides, as well as hypothalamic and peripheral target gland hormones, acting on their respective cellular receptors via complex intracellular signaling pathways (1). Previous studies have demonstrated that nontumorous pituitary cells can adapt to functional demands requiring hypersecretion of a specific hormone, using different mechanisms. Childs and Unabia (2) reported that activin stimulates the synthesis of gonadotropin-releasing hormone $(\mathrm{GnRH})$ receptor, suggesting that activin plays an important role in the increase in numbers of GnRH target cells normally seen before ovulation. Despite specific receptor up-regulation, it is well-known that stimulation of pituitary cells causes morphologic changes characterized by increased size (hypertrophy) and number (hyperplasia). Cellular hypertrophy is easily explained by marked development of cytoplasmic organelles and/or increased number of secretory granules. To understand the development of pituitary hyperplasia, two explanations can be postulated: an increase in cell number due to multiplication of the stimulated cell type (3-5) or a differentiation of stem cells into mature cells of that cell type $(6,7)$. A third mechanism is also conceivable that implies that cells of one line 
may transform to another cell line, acquiring a change in their morphologic features and secretory capacity-a process termed transdifferentiation (8). Such an interconversion is viewed as not a direct process but as occurring through transitional cells exhibiting morphologic and functional components common to both cell types.

The presence of bihormonal acidophils-termed mammosomatotrophs, which are simultaneously immunoreactive for growth hormone (GH) and prolactin (PRL) - have been reported in several animal species, such as rat, mice, cows, and so on, under physiological conditions (9). Mammosomatotrophs have also been demonstrated in nontumorous human pituitaries. They are especially abundant during pregnancy and lactation, associated with massive lactotroph hyperplasia. Such an upsurge of bihormonal cells is concordant with the role of mammosomatotrophs in the functional differentiation of GH-only to PRL-only cells. The opposite of this process, that is, the transformation of PRL-immunoreactive cells into GH-immunoreactive cells, was observed in bovine and rat pituitaries $(10,11)$. The possible role of mammosomatotrophs in the conversion of PRL-only to GH-only cells, however, has not been sufficiently investigated.

To our knowledge, the present study is the first that demonstrates marked increase of mammosomatotrophs in nontumorous human pituitaries displaying somatotroph hyperplasia associated clinically with acromegaly. For comparison, samples of pituitary tissue from a patient with idiopathic lactotroph hyperplasia, as well as from a patient with secondary lactotroph hyperplasia, were also included in the study. Our results support the idea that the mammosomatotroph serves as an obligatory transitional cell in the interconversion of somatotroph and lactotroph in the human pituitary.

\section{MATERIAL AND METHODS}

\section{Case Histories}

\section{Case 1}

This 38-year-old man had a longstanding acromegaly. Magnetic resonance imaging demonstrated an enlarged pituitary. During transsphenoidal surgery, no discrete adenoma was found, and the diffuse enlargement of the gland suggested hyperplastic growth. Thus, instead of radical surgery, a biopsy was taken from the area that appeared to be most involved. Subsequent studies revealed that this patient had a gonadotropin hormone-releasing hormone-producing bronchial carcinoid, which was removed 2 years after pituitary surgery.

\section{Case 2}

This 28-year-old woman had a history of longstanding acromegaly as well as of menstrual irregularities and galactorrhea. Ten years previously, she had a left upper lobectomy for removal of a bronchial carcinoid. She was known to have metastatic disease. Magnetic resonance imaging documented a diffusely enlarged pituitary. Because treatment with octreotide, a long-acting somatostatin analogue, for 4 months was not effective for, size reduction of the pituitary, hypophysectomy was performed (12).

\section{Case 3}

This 38-year-old mother of two complained of headaches as well as of menstrual irregularities for 11 years. Magnetic resonance imaging showed enlargement of the left side of her pituitary. Blood PRL level was $256 \mathrm{ng} / \mathrm{mL}$, with exaggerated response (up to $1100 \mathrm{ng} / \mathrm{mL}$ ) after intravenous thyrotropinreleasing hormone (TRH) administration. Her baseline TSH level was also slightly elevated at 6.8 $\mathrm{mU} / \mathrm{L}$, rising to $48.5 \mathrm{mU} / \mathrm{L}$ after TRH stimulation. The blood levels of other pituitary hormones were within the normal range. Transsphenoidal removal of the affected portion of the pituitary revealed no discrete adenoma. Postoperatively, her blood PRL remained elevated (13).

\section{Case 4}

This 14-year-old boy presented with a cystic suprasellar lesion as well as with hypopituitarism and diabetes insipidus. The tumor, a craniopharyngioma, was surgically removed, and the adjacent adenohypophysis was biopsied.

\section{Histologic and Immunocytochemical Studies}

Tissues were fixed in $10 \%$ buffered formalin, dehydrated in graded ethanol, paraffin embedded, and sectioned at $5 \mu \mathrm{m}$.

For histology, the sections were stained with hematoxylin-eosin (H\&E), the periodic acid-Schiff (periodic acid-Schiff) method, and the GordonSweet silver method for demonstration of reticulin fibers. Immunocytochemical studies employed the streptavidin-biotin-peroxidase complex technique (14). Antibodies directed toward all pituitary hormones were applied in all cases. Antisera were directed against the following: GH (DAKO, Carpinteria, CA), PRL (donated by Dr. Friesen, University of Manitoba, Winnipeg, Canada), thyroid-stimulating hormone ( $\beta$-TSH, Novocastra, Burlington, Canada), follicle-stimulating hormone $(\beta-\mathrm{FSH}$, donated by Dr. Parlow, National Hormone and Pituitary Distribution Agency, Baltimore, MD), luteinizing hormone ( $\beta$-LH, donated by Dr. Parlow, National Hormone and Pituitary Distribution Agency), and 
$\alpha$-subunit of glycoprotein hormones (Biogenex, San Ramon, CA). Details of immunocytochemistry for adenohypophysial hormones, including dilution of antibodies, duration of exposure, and control procedures, have been described elsewhere $(15,16)$.

\section{Ultrastructural Studies}

For transmission electron microscopy (TEM), additional specimens were fixed overnight at $4{ }^{\circ} \mathrm{C}$ in $2.5 \%$ glutaraldehyde in Sorensen's phosphate buffer ( $\mathrm{pH}$ 7.4), osmicated for 1 hour at room temperature in $1 \% \mathrm{OsO}_{4}$ in Millonig's buffer ( $\mathrm{pH} 7.4$ ), dehydrated in a graded ethanol series, embedded in an Epon-Araldite mixture, and examined on a Philips 410LS transmission electron microscope.

To assess subcellular localization of GH and PRL in mammosomatotrophs, immunoelectron microscopy (IEM) was performed using the doubleimmunogold method of Bendayan (17). Before labeling, ultrathin sections were pretreated for 1 hour in a saturated aqueous solution of sodium metaperiodate (18). One side of the grids was then incubated at $37{ }^{\circ} \mathrm{C}$ for 12 hours with specific antisera directed toward either GH or PRL. Subsequently, the grids were treated at $37{ }^{\circ} \mathrm{C}$ for 1 hour with gold-labeled, goat anti-rabbit IgG (Biocell Research Laboratories, Cardiff, UK); particle diameters were either 10 or $20 \mathrm{~nm}$. Between each step, grids were washed in $0.2 \mathrm{M}$ phosphate buffered saline ( $\mathrm{pH} 7.5)$ admixed with $0.2 \%$ cold-water fish gelatin (SigmaAldrich, Oakville, Ontario, Canada). For double immunostaining, the procedure was repeated on the other side of the grid using another specific antibody and a colloidal gold conjugate of a different size. A 10-nm gold particle was used to visualize GH in Cases 1 and 2 and PRL in Cases 3 and 4, whereas a 20-nm gold particle was used to visualize PRL in Cases 1 and 2 and GH in Cases 3 and 4. After immunolabeling, sections were stained with uranyl acetate and examined on a Philips 410 LS transmission electron microscope.

\section{In Situ Hybridization Studies}

In situ hybridization (ISH) was performed as described elsewhere $(15,19)$. The $35^{\mathrm{S}}$ - labeled probes were diluted in hybridization buffer, and $1 \times 10^{6}$ cpm for PRL and GH were used in ISH. Combined ISH and immunohistochemistry procedures were undertaken with immunohistochemistry initiated after hybridization and $2 \times$ SSC washings as described elsewhere $(15,19)$. A GH antiserum $(1: 1000)$ and PRL antiserum (1:1000) donated by Dr. Parlow of the National Hormone and Pituitary Distribution Agency was used with the avidin-biotin-peroxidase system. Autoradiographic detection of the hybrids was carried out by dipping in Kodak NTB2 emul- sion diluted 1:1 with distilled water containing $0.3 \mathrm{M}$ ammonium acetate. Control for in situ hybridization consisted of using GH and PRL sense probes.

\section{RESULTS}

\section{Light-Microscopic Findings}

In the two cases of acromegaly, portions of nontumorous adenohypophysis were identified as displaying features of somatotroph hyperplasia. The GordonSweet silver stain demonstrated the preservation of the acinar architecture; however, the acini were larger than normal, irregular, and contained considerably more cells than usual. Immunostaining revealed an abundance of cells immunoreactive for GH in the enlarged acini. Immunostaining documented cells immunoreactive for other pituitary hormones interspersed with the hyperplastic somatotrophs.

The pituitary specimens from Cases 3 and 4 showed preserved, but markedly distorted, acinar architecture, and immunostaining documented predominance and massive immunoreactivity of lactotrophs. Within the lesion of the 38-year-old woman, diagnosed as the rare idiopathic lactotroph hyperplasia, the other types of interspersed adenohypophysial cells displayed normal morphology and corresponding immunoreactivity. In the pituitary specimen of the 14-year-old boy with marked lactotroph hyperplasia, secondary to suprasellar craniopharyngioma, somatotrophs and corticotrophs exhibited normal morphology and immunopositivity, whereas the gonadotrophs and thyrotrophs were extremely scanty and small, showing weak immunoreactivity.

\section{Ultrastructural Findings}

Fragments of nontumorous adenohypophysis were recognized in the specimens of acromegalic patients. The acinar architecture was preserved, but the acini were expanded in several areas. A strong predominance of somatotrophs was evident in all samples studied. The somatotrophs were admixed with a variable number of thyrotrophs, gonadotrophs, and corticotrophs. Cells having the ultrastructural phenotype of lactotrophs were conclusively identified in all specimens.

The nucleus of somatotrophs possessed prominent nucleolus and scarcity of nuclear heterochromatin. The cytoplasm contained an unusually large and active Golgi apparatus. The majority of somatotrophs were heavily granulated, with abnormally large secretory granules reaching or exceeding 1000 $\mathrm{nm}$ in diameter. A few somatotrophs contained fibrous bodies as well. It is of note that fibrous bodies are not present in normal somatotrophs, but they 
may be present in somatotroph or mammosomatotroph hyperplasia.

IEM demonstrated that most of the cells in the hyperplastic area were immunolabeled only for GH. These cells showed features of typical GH secretory cells. They were spherical or polygonal with variably developed cytoplasmic organelles. The cytoplasm of some cells possessed spherical secretory granules measuring approximately $400 \mathrm{~nm}$ in diameter. Occasionally, cells belonging to this phenotype contained a low proportion (1-5\%) of smaller secretory granules (approximately $200 \mathrm{~nm}$ in mean diameter) that labeled for both GH and PRL.

In contrast to somatotrophs, monohormonal lactotrophs were rarely detected in the specimens.

The double-immunogold method revealed that the cell type bearing ultrastructural features of lactotrophs contained GH and PRL simultaneously in their secretory granules (Fig. 1). The obviously bihormonal mammosomatotrophs often appeared adjacent to somatotrophs. The mammosomatotrophs contained small as well as large secretory granules. The secretory granules were mainly bihormonal, labeling for both GH and PRL, admixed with secretory granules immunoreactive for either GH or PRL alone (Fig. 2).

As opposed to the ultrastructural similarity of somatotroph hyperplasias, the TEM features of the two cases of lactotroph hyperplasias were markedly different. The TEM appearance of the idiopathic lactotroph hyperplasia was dominated by active lactotrophs with variable granularity as well as by mammosomatotrophs having large secretory gran-

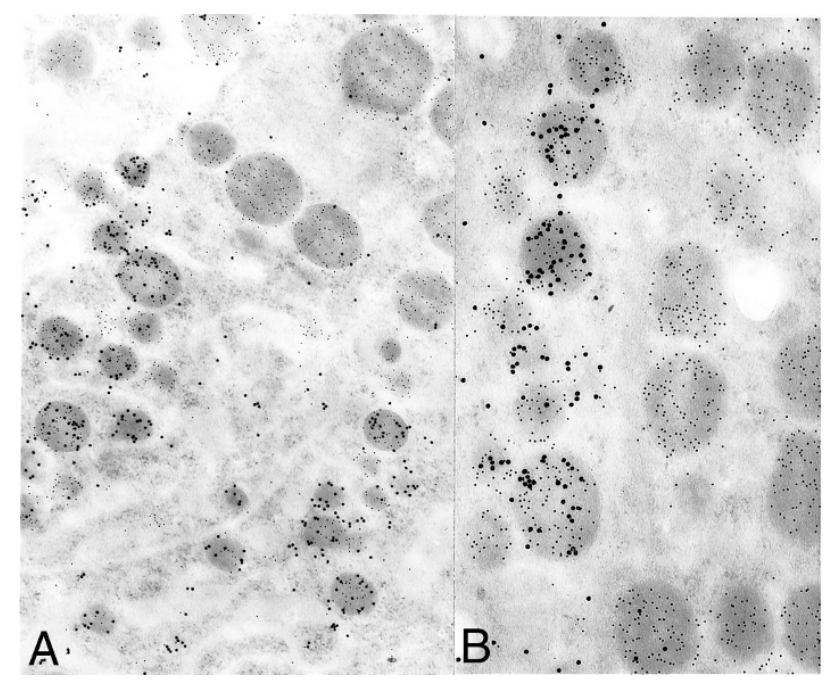

FIGURE 1. Somatotroph hyperplasia, Case 1. A, The secretory granules of cells having features of lactotrophs are labeled for both growth hormone $(\mathrm{GH})$ and prolactin (PRL). One cell (right upper) is labeled for GH only, 14,200×. B, Mammosomatotroph (left) is heavily labeled for both GH and PRL, whereas a somatotroph (right) carries only the GH label, $24,000 \times$. There is only light, nonspecific background labeling outside the secretory granules. Immunoelectron microscopy using double-immunogold labeling was used. GH: $10 \mathrm{~nm}$, PRL: $20 \mathrm{~nm}$.

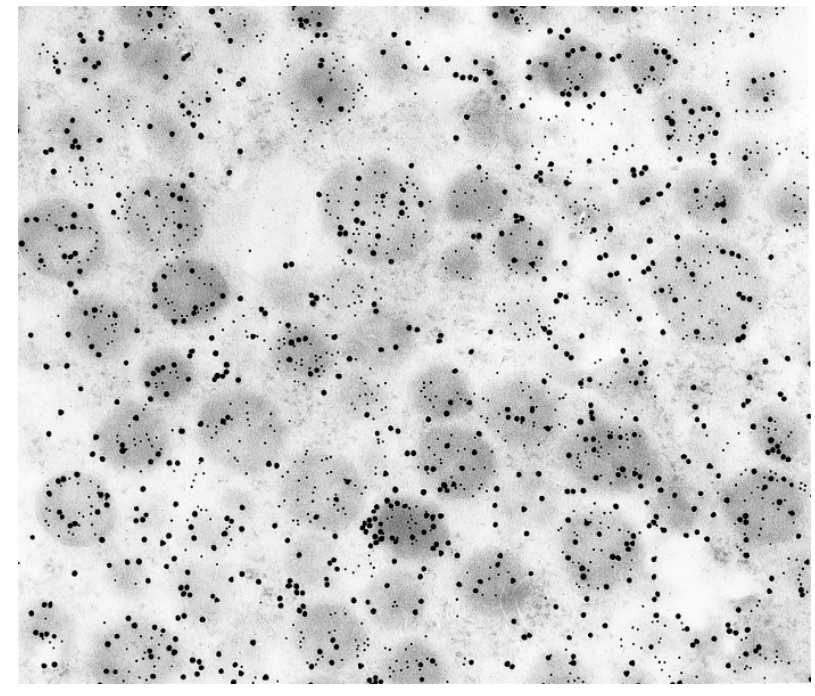

FIGURE 2. Same case as in Figure 1. Mammosomatotroph possessing both small and large secretory granules. Most secretory granules are bihormonal. Immunoelectron microscopy using double-immunogold labeling, 28,000×. Growth hormone $(\mathrm{GH}): 10 \mathrm{~nm}$, prolactin $(\mathrm{PRL}): 20$ $\mathrm{nm}$.

ules and exhibiting granule exocytoses (Fig. 3). Remarkably, endocrine amyloid, which may be seen in somatotroph adenomas but is not known to occur in the normal gland, was also observed. The other cell types showed normal features. IEM indicated the absence of strictly monohormonal somatotrophs in the sample. Also contrary to expectation, the majority of cells were not monohormonal lactotrophs but were mammosomatotrophs with variable secretory granule size and highly variable proportions of the GH and PRL labels (Fig. 4).

The secondary lactotroph hyperplasia in the 14year-old male patient was characterized by large, stimulated lactotrophs possessing masses of rough endoplasmic reticulum (RER), prominent Golgi complex, and very few and small secretory granules, suggesting rapid synthesis and release of the hormone (Fig. 5). Somatotrophs were typical, with large, ovoid secretory granules (Fig. 6). The TEM features of corticotrophs appeared normal, whereas gonadotrophs and thyrotrophs were scanty and small with poorly developed organelles, minute secretory granules, and several lysosomes, indicating low endocrine activity. By IEM, this was the only lesion displaying immunoreactivity true to this phenotype. Somatotrophs labeled only for GH; lactotrophs bore only the PRL label, with the exception of occasional double-labeled immature secretory granules within the Golgi area. Only one mammosomatotroph was encountered with typical features (Fig. 7).

\section{ISH and Immunohistochemical Findings}

ISH for GH mRNA demonstrated strong signal in both cases of somatotroph hyperplasia, whereas 


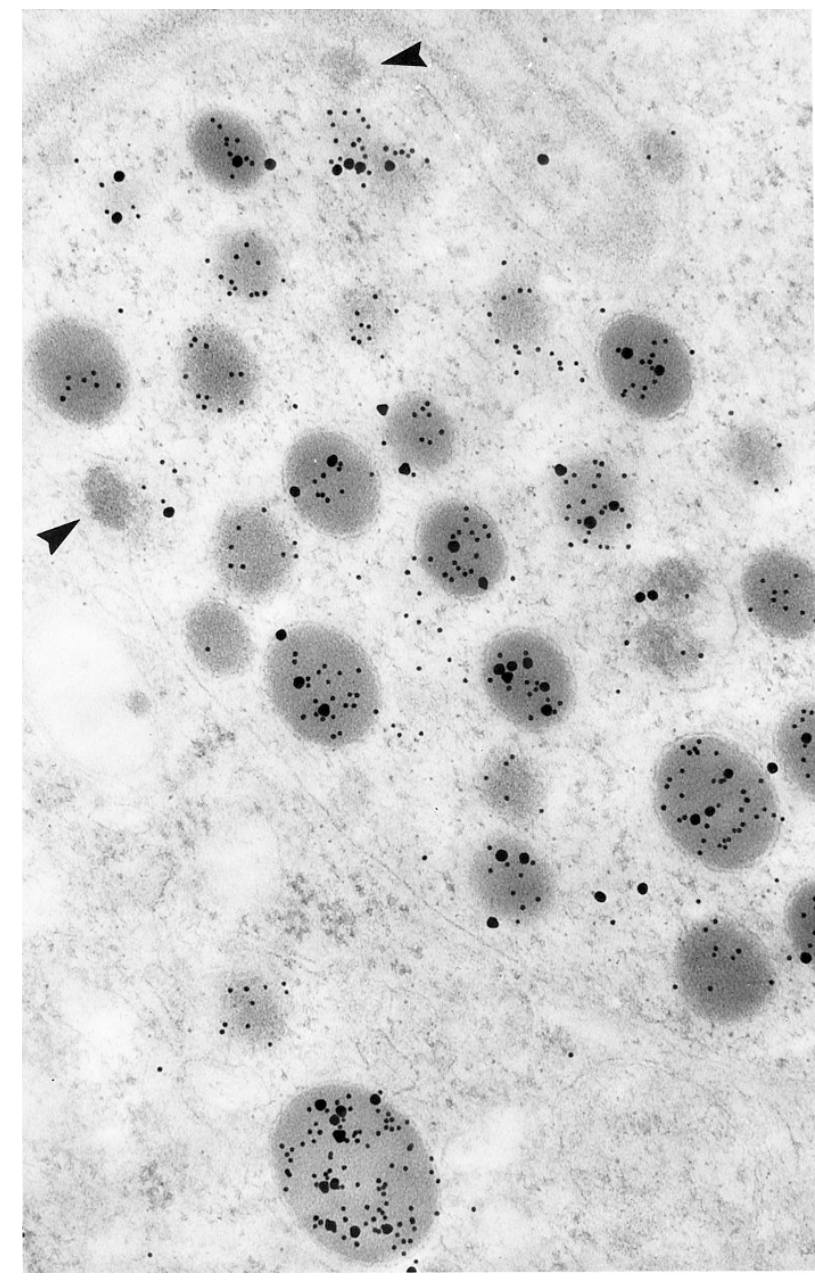

FIGURE 3. Idiopathic lactotroph hyperplasia, Case 3. Part of a mammosomatotroph displaying two granule extrusion sites (arrowheads) is shown. The secretory granules are of variable sizes and are either bihormonal or labeled for prolactin (PRL) only, 50,400 $\times$. Immunoelectron microscopy using double-immunogold labeling. Growth hormone (GH): $20 \mathrm{~nm}$, PRL: $10 \mathrm{~nm}$.

immunohistochemical (IHC) studies of PRL documented the presence of bihormonal mammosomatotrophs. Combination of ISH for the PRL gene and immunostaining for GH clearly documented that monohormonal lactotrophs were scanty in such pituitaries.

The results of combined ISH and IHC in the two patients with lactotroph hyperplasia were different. Simultaneous ISH and IHC for PRL documented intense hybridization signal and immunoreactivity in both specimens. In the patient with idiopathic lactotroph hyperplasia, ISH for PRL and IHC for GH evidenced the dominance of mammosomatotrophs, whereas monohormonal somatotrophs were scanty. In the pituitary of the young male patient with secondary lactotroph hyperplasia, ISH for PRL and IHC for GH demonstrated the clear separation of the two cell types, documenting only a few bihormonal mammosomatotrophs in the pituitary of this patient.

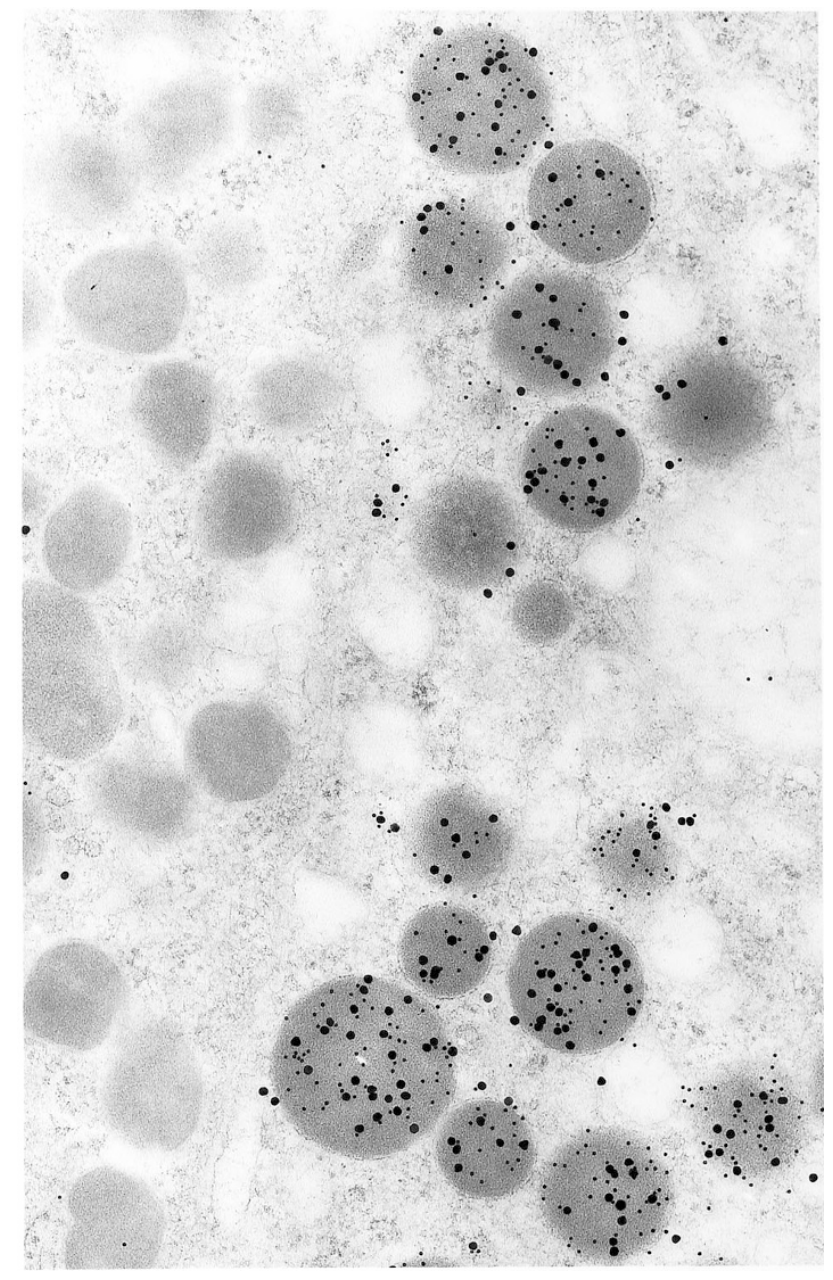

FIGURE 4. Same case as in Figure 3. A heavily labeled bihormonal mammosomatotroph is shown (right) adjacent to an immunonegative cell, 40,560×. Immunoelectron microscopy using double-immunogold labeling. Growth hormone $(\mathrm{GH}): 20 \mathrm{~nm}$, prolactin (PRL): $10 \mathrm{~nm}$.

\section{DISCUSSION}

Since the abandonment of the restrictive one cell-one hormone theory, the adenohypophysis has emerged as a remarkably plastic organ. It is able to change its size and increase or reduce the number of specific cell populations to meet the actual requirements of the body. Previous studies have suggested that somatotrophs, the most abundant pituitary cell type, could play a key role in pituitary plasticity (20). In vitro studies have demonstrated that transdifferentiation of somatotrophs contributes to the preovulatory increase in the number of gonadotrophs (2). The transformation of somatotrophs into gonadotrophs is presumably a complex process, the first step of which could be the expression of $\mathrm{GnRH}$ receptor in somatotrophs. These findings are supported by immunocytochemical detection of Pit-1 immunopositive gonadotrophs in the nontumorous female rat pituitary (21), Pit-1 being an important transcription factor necessary for the expression of GH, PRL, and $\beta$-TSH subunit genes $(22,23)$. 


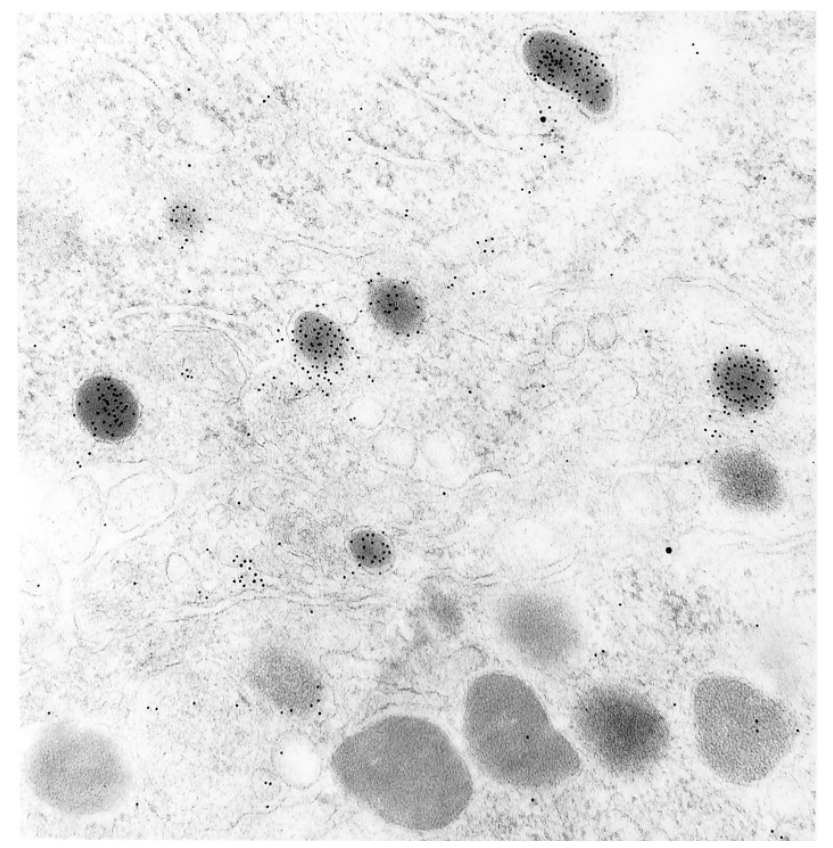

FIGURE 5. Same case as in Figure 6. Shown adjacent to an immunonegative cell (bottom), the sparse secretory granules of a hyperplastic lactotroph label only for PRL, 29,400×. Immunoelectron microscopy using double-immunogold labeling. Growth hormone (GH): $20 \mathrm{~nm}$, prolactin (PRL): $10 \mathrm{~nm}$.

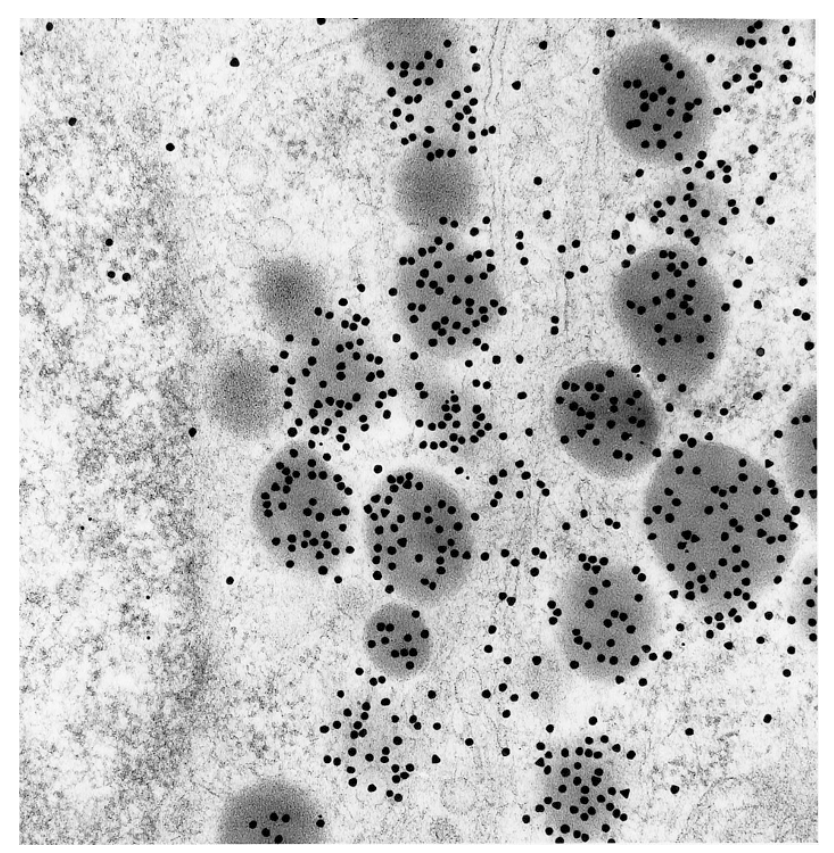

FIGURE 6. Secondary lactotroph hyperplasia, Case 4. Portions of two heavily labeled monohormonal somatotrophs are shown, 37,800× Immunoelectron microscopy using double-immunogold labeling. Growth hormone (GH): $20 \mathrm{~nm}$, prolactin (PRL): $10 \mathrm{~nm}$.

In contrast to the somatotroph-gonadotroph conversion, transdifferentiation between adenohypophysial cell types belonging to the Pit-1 lineage is easier to understand. Transdifferentiation may occur frequently under physiological and pathological conditions. Mammosomatotrophs have been de- scribed in association with hyperprolactinemia reported in different species (24-28). Studies of the hyperplastic human pituitary in pregnant women documented a marked increase of mammosomatotrophs and the decrease of somatotrophs, strongly suggesting that a contingent of PRLproducing cells is recruited from somatotrophs. In this process, mammosomatotrophs may serve as a transitional cell type $(10,26,29)$. In rats made hypothyroid by propylthiouracil administration, somatotrophs transform to stimulated thyrotrophs through bihormonal transitional cells, so-called thyrosomatotrophs that exhibit features common to both cell types (8). Presence of thyrosomatotrophs in human pituitary has been recently reported in cases of thyrotroph hyperplasia due to protracted primary hypothyroidism, supporting the notion that such cells contribute to the development of new thyrotrophs in the human gland as well (20). Previous experimental studies in rats with chemically induced hypothyroidism demonstrated that transdifferentiation of somatotrophs to thyrotrophs is reversible because thyrotrophs reverted to somatotrophs after discontinuation of propylthiouracil administration (8). However, the subcellular events leading to the reversion of bihormonal thyrosomatotroph to somatrotrophs has not been documented. The participation of plurihormonal cells in the reverse transdifferentiation of somatotrophs and other pituitary cell types was also investigated. In vitro and IEM studies demonstrated that in human fetal pituitaries, GH-secreting cells could act as progenitors of PRL secreting cells via an intermediate cell type, the mammosomatotrophs (30, 31). The close association between human somatotrophs and lactotrophs is similar to that observed in fetal bovine (32) and neonatal rat pituitaries (33), in which adenohypophysial cells producing PRL were mammosomatotrophs. Several studies have demonstrated that the conversion of somatotrophs to PRL-secreting cells is bidirectional $(10,11)$. Thus, the proportion of cells that secreted GH alone increased markedly, and the percentage that released only PRL decreased extensively in human and rat pituitaries after gestation and lactation $(10,27,34)$.

The role of mammosomatotrophs in the development of lactotroph hyperplasia was fully confirmed in the present study: the majority of lactotrophs in the case of idiopathic lactotroph hyperplasia were mammosomatotrophs. However, one should not ignore the finding that lactotroph hyperplasia in the 14-year-old male patient was monohormonal and that mammosomatotrophs were only occasionally noted. The pituitary ultrastructure in this case also indicated marked hypoactivity of gonadotrophs and thyrotrophs, and the boy's diabetes insipidus pointed to the impaired secretion and/or delivery of hypothalamic regulatory hormones. Thus, it is 


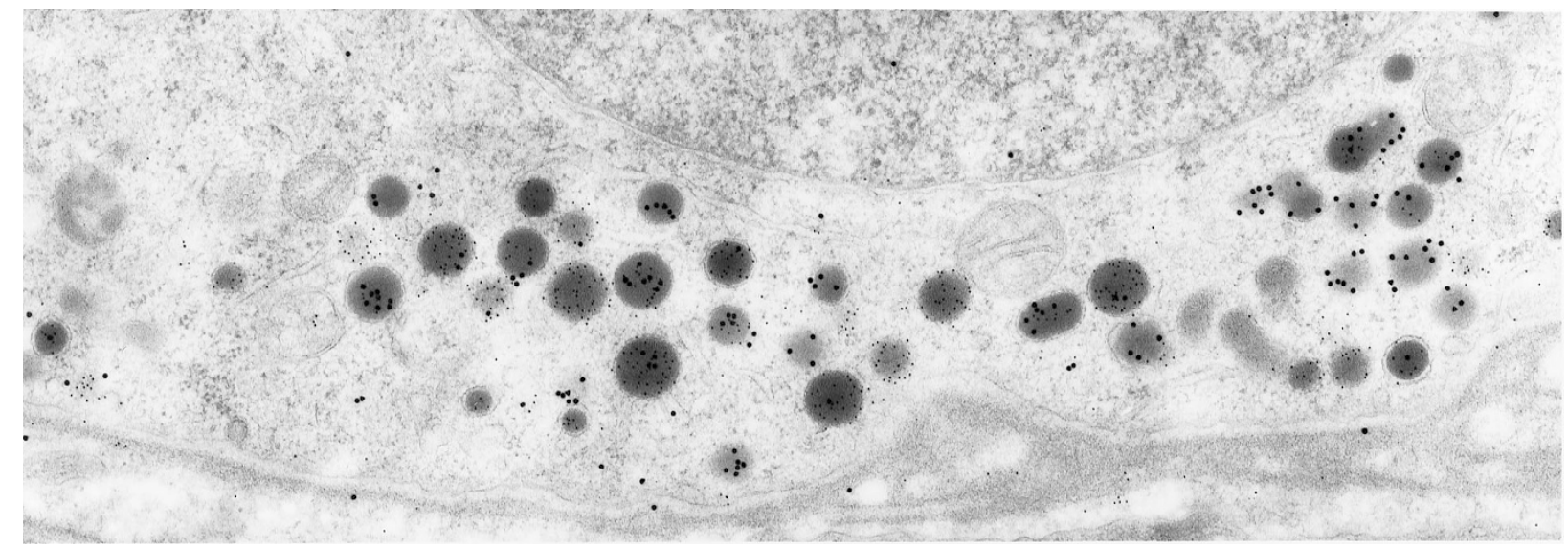

FIGURE 7. Same case as in Figures 5 and 6 . A rare mammosomatotroph is shown possessing both monohormonal and bihormonal small secretory granules, 23,920×. Immunoelectron microscopy using double-immunogold labeling. Growth hormone (GH): $20 \mathrm{~nm}$, prolactin (PRL): $10 \mathrm{~nm}$.

reasonable to suggest that the participation of mammosomatotrophs in lactotroph hyperplasia is not unconditional but is subject to the interplay of other factors determining the endocrine milieu.

This study conclusively demonstrates that the mammosomatotroph plays an important role in the development of somatotroph hyperplasia in the human pituitary as well. Because monohormonal lactotrophs were not apparent in the hyperplastic areas and because some glandular cells with somatotroph phenotype contained bihormonal secretory granules, the presence of mammosomatotroph could be regarded as the morphologic manifestation of an intermediate step in the transdifferentiation of lactotrophs to somatotrophs. Transdifferentiation in nontumorous pituitaries, as in somatotroph hyperplasia, is a reversible process apparently due to transcriptional or posttranscriptional changes requiring the existence of the same mechanism for the activation of GH synthesis and reduction and/or elimination of PRL release. Porter et al. (10) proposed demethylation and methylation of the GH and PRL genes, respectively, to be the genetic events likely to occur after weaning and that result in GH secretion and no PRL synthesis. Recent studies have provided information on the molecular basis of the specific regulation of PRL and GH gene transcription that could play an important role in the process of transdifferentiation. It was suggested that Pit-1 expression may directly or indirectly regulate somatotrophs and lactotrophs through activation of GRH and somatostatin receptors on the one hand and of dopamine on the other hand (35-37). In addition to Pit-1, other transcription factors and homeobox genes may be required for generating various pituitary cell phenotypes belonging to the Pit-1 lineage (38-40).

One intriguing fact emerging from our studies should be commented upon briefly. In three of the four patients with pituitary hyperplasia, the immunoreactivities did not correspond to the morphologic phenotypes. In somatotroph, hyperplasia cells having the ultrastructural appearance of lactotrophs produced GH as well, whereas in lactotroph, hyperplasia cells possessing somatotroph features were evidently bihormonal. The question is whether these findings are in conflict with the Virchowian principles or whether they simply re-
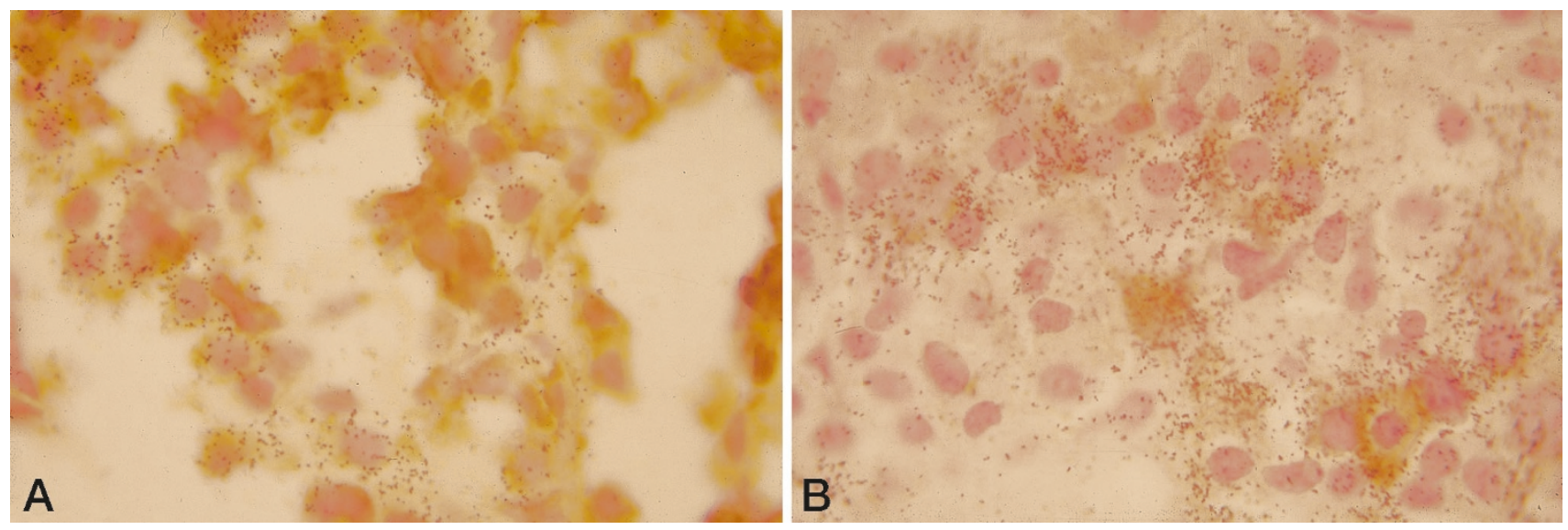
flect the basic contradiction of pathology, that is, the need to precisely define an ongoing pathological process based on static images provided by morphologic methods. In the present studies, the apparently discrepant results may signify that the morphologic changes lag behind the functional ones. In this context, the combination of electron microscopy and immunocytochemistry may provide an insight into the ongoing process of transdifferentiation and the innate plasticity of adenohypophysial cells.

Acknowledgment: This study was supported in part by the Research Council of St. Michael's Hospital, Mr. and Mrs. Stephen Jarislowsky, and the Lloyd Carr-Harris foundation. SV was supported by a research grant from the University of Santiago de Compostela, Spain. The authors are indebted to Mrs. Sandy Briggs, Ms. Sandy Cohen, and Mrs. Elizabeth McDermott for the technical assistance and to the staff of St. Michael's Health Sciences Library for their contribution in this study.

\section{REFERENCES}

1. Ray D, Melmed S. Pituitary cytokine and growth factor expression and action. Endocr Rev 1997;18:206-28.

2. Childs GV, Unabia G. Cytochemical studies of the effects of activin on gonadotropin- releasing hormone (GnRH) binding by pituitary gonadotropes and growth hormone cells. J Histochem Cytochem 1997;45:1603-10.

3. Stratmann IE, Ezrin C, Sellers EA, Simon GT. The origin of thyroidectomy cells as revealed by high resolution radioautography. Endocrinology 1972;90:728-34.

4. Lloyd HM, Meares JD, Jacobi J. Effects of oestrogen and bromocryptine on in vivo secretion and mitosis in prolactin cells. Nature 1975;255:497-8.

5. Takahashi S, Okazaki K, Kawashima S. Mitotic activity of prolactin cells in the pituitary glands of male and female rats of different ages. Cell Tissue Res 1984;235:497-502.

6. Severinghaus AE. Cellular changes in the anterior hypophysis with special references to its secretory activities. Physiol Rev 1937;17:556-88.

7. Yoshimura F, Harumiya K, Ishikawa H, Otsuka Y. Differentiation of isolated chromophobes into acidophils or basophils when transplanted into the hypophysiotrophic area of hypothalamus. Endocrinol Jpn 1969;16:531-40.

8. Horvath E, Lloyd RV, Kovacs K. Propylthiouracyl-induced hypothyroidism results in reversible transdifferentiation of somatotrophs into thyroidectomy cells. A morphologic study of the rat pituitary including immunoelectron microscopy. Lab Invest 1990;63:511-20.

9. Frawley LS, Boockfor FR. Mammosomatotropes: presence and functions in normal and neoplastic pituitary tissue. Endocr Rev 1991;12:337-55.

10. Porter TE, Wiles CD, Frawley LS. Evidence for bidirectional interconversion of mammotropes and somatotropes: rapid reversion of acidophilic cell types to pregestational proportions after weaning. Endocrinology 1991;129:1215-20.

11. Kineman RD, Henricks DM, Faught WJ, Frawley LS. Fluctuations in the proportions of growth hormone- and prolactinsecreting cells during the bovine estrous cycle. Endocrinology 1991;129:1221-5.
12. Ezzat S, Asa SL, Stefaneanu L, Whittom R, Smyth HS, Horvath E, et al. Somatotroph hyperplasia without pituitary adenoma associated with a long standing growth hormonereleasing hormone-producing bronchial carcinoid. J Clin Endocrinol Metab 1994;78:555-60.

13. Jay V, Kovacs K, Horvath E, Lloyd RV, Smyth HS. Idiopathic prolactin cell hyperplasia of the pituitary mimicking prolactin cell adenoma: a morphological study including immunocytochemistry, electron microscopy, and in situ hybridization. Acta Neuropathol (Berl) 1991;82:147-51.

14. Hsu SM, Raine L, Fanger H. Use of avidin-biotin-peroxidase complex $(\mathrm{ABC})$ in immunoperoxidase techniques: a comparison between $\mathrm{ABC}$ and unlabeled antibody (PAP) procedures. J Histochem Cytochem 1981;29:577-80.

15. Kovacs K, Lloyd R, Horvath E, Asa SL, Stefaneanu L, Killinger DW, et al. Silent somatotroph adenomas of the human pituitary. A morphologic study of three cases including immunocytochemistry, electron microscopy, in vitro examination, and in situ hybridization. Am J Pathol 1989;134:345-53.

16. Kovacs K, Stefaneanu L, Horvath E, Lloyd RV, Lancranjan I, Buchfelder M, et al. Effect of dopamine agonist medication on prolactin producing pituitary adenomas. A morphological study including immunocytochemistry, electron microscopy and in situ hybridization. Virchows Arch A Pathol Anat Histopathol 1991;418:439-46.

17. Bendayan M. Double immunocytochemical labeling applying the protein A-gold technique. J Histochem Cytochem 1982;30:81-5.

18. Bendayan M, Zollinger M. Ultrastructural localization of antigenic sites on osmium-fixed tissues applying the protein A-gold technique. J Histochem Cytochem 1983;31:101-9.

19. Lloyd RV, Cano M, Chandler WF, Barkan AL, Horvath E, Kovacs K. Human growth hormone and prolactin secreting pituitary adenomas analyzed by in situ hybridization. Am J Pathol 1989;134:605-13.

20. Vidal S, Horvath E, Kovacs K, Cohen SM, Lloyd RV, Scheithauer BW. Transdifferentiation of somatotrophs to thyrotrophs in the pituitary of patients with protracted primary hypothyroidism. Virchows Arch 2000;1:43-51.

21. Vidal S, Roman A, Oliveira MC, De La Cruz LF, Moya L. Simultaneous localization of Pit-1 protein and gonadotropins on the same cell type in the anterior pituitary glands of the rat. Histochem Cell Biol 1998;110:183-8.

22. Li S, Crenshaw EB III, Rawson EJ, Simmons DM, Swanson LW, Rosenfeld MG. Dwarf locus mutants lacking three pituitary cell types result from mutations in the POU-domain gene pit-1. Nature 1990;347:528-33.

23. Ryan AK, Rosenfeld MG. POU domain family values: flexibility, partnerships, and developmental codes. Genes Dev 1997;11:1207-25.

24. Ishibashi T, Shiino M. Subcellular localization of prolactin in the anterior pituitary cells of the female Japanese house bat, Pipistrellus abramus. Endocrinology 1989;124:1056-63.

25. Ishibashi T, Shiino M. Co-localization pattern of growth hormone (GH) and prolactin (PRL) within the anterior pituitary cells in the female rat and female musk shrew. Anat Rec 1989;223:185-93.

26. Porter TE, Hill JB, Wiles CD, Frawley LS. Is the mammosomatotrope a transitional cell for the functional interconversion of growth hormone- and prolactin-secreting cells? Suggestive evidence from virgin, gestating, and lactating rats. Endocrinology 1990;127:2789-94.

27. Stefaneanu L, Kovacs K, Lloyd RV, Scheithauer BW, Young WF Jr, Sano T, et al. Pituitary lactotrophs and somatotrophs in pregnancy: a correlative in situ hybridization and immunocytochemical study. Virchows Arch B Cell Pathol 1992;62: 291-6.

28. Vidal S, Roman A, Moya L. Description of two types of mammosomatotropes in mink (Mustela vison) adenohy- 
pophysis: changes in the population of mammosomatotropes under different physiological conditions. Acta Anat (Basel) 1997;159:209-17.

29. Kineman RD, Faught WJ, Frawley LS. Steroids can modulate transdifferentiation of prolactin and growth hormone cells in bovine pituitary cultures. Endocrinology 1992;130:3289-94.

30. Asa SL, Kovacs K, Horvath E, Losinski NE, Laszlo FA, Domokos I, et al. Human fetal adenohypophysis. Electron microscopic and ultrastructural immunocytochemical analysis. Neuroendocrinology 1988;48:423-31.

31. Mulchahey JJ, Jaffe RB. Detection of a potential progenitor cell in the human fetal pituitary that secretes both growth hormone and prolactin. J Clin Endocrinol Metab 1988;66:24-32.

32. Kineman RD, Faught WJ, Frawley LS. The ontogenic and functional relationships between growth hormone- and prolactin-releasing cells during the development of the bovine pituitary. J Endocrinol 1992;134:91-6.

33. Hoeffler JP, Boockfor FR, Frawley LS. Ontogeny of prolactin cells in neonatal rats: initial prolactin secretors also release growth hormone. Endocrinology 1985;117:187-95.

34. Scheithauer BW, Sano T, Kovacs KT, Young WF Jr, Ryan N, Randall RV. The pituitary gland in pregnancy: a clinicopath- ologic and immunohistochemical study of 69 cases. Mayo Clin Proc 1990;65:461-74.

35. Lin C, Lin SC, Chang CP, Rosenfeld MG. Pit-1-dependent expression of the receptor for growth hormone releasing factor mediates pituitary cell growth. Nature 1992;360:765-8.

36. Day RN, Liu J, Sundmark V, Kawecki M, Berry D, Elsholtz HP. Selective inhibition of prolactin gene transcription by the ETS-2 repressor factor. J Biol Chem 1998;273:31909-15.

37. Miller TL, Godfrey PA, Dealmeida VI, Mayo KE. The rat growth hormone-releasing hormone receptor gene: structure, regulation, and generation of receptor isoforms with different signaling properties. Endocrinology 1999;140:415265.

38. Watkins-Chow DE, Camper SA. How many homeobox genes does it take to make a pituitary gland? Trends Genet 1998; $14: 284-90$.

39. Drouin J, Lamolet B, Lamonerie T, Lanctot C, Tremblay JJ. The PTX family of homeodomain transcription factors during pituitary developments. Mol Cell Endocrinol 1998;140:31-6.

40. Burrows HL, Douglas KR, Seasholtz AF, Camper SA. Geneology of the anterior pituitary gland: tracing a family tree. Trends Endocrinol Metab 1999;10:343-52. 